Physical Strength as a Heuristic Cue of Political Conservatism

$150($ Abstract $)+5621($ Body $)+1554($ References $)+31($ Figures $)+35($ Notes $)=7391$ 


\begin{abstract}
Social bargaining models posit physically formidable men tend to pursue strategies for acquiring resources and status through direct competition and promoting hierarchical social organization. Previous research indicates that formidable men espouse more conservative political viewpoints, as a means of advancing social policies favoring use of aggressive bargaining and hierarchymaintenance strategies. If the mind is designed to utilize probabilistic cues of behavioral strategies, physical strength may function as a heuristic cue of political conservatism. Participants in three studies inferred conservatism of physically strong and weak men. Physically strong men were consistently perceived as more conservative (Studies 1 and 2). Inferences from strength cues were moderated neither by type of conservatism (i.e., fiscal versus social) nor presence of wealth cues. Inferences further extended to tradition-based and libertarian moral foundations domains (Study 3). We frame results using an affordance management framework, suggesting individuals utilize cues to formidability as heuristics to infer political attitudes.

Keywords: Formidability, Strength, Politics, Conservatism, Coalition, Stereotyping
\end{abstract}




\section{Physical Strength as a Heuristic Cue of Political Conservatism}

Group living can generate net benefits for members of communities, but also creates various challenges and problems to be solved. As such, humans' evaluative psychology in identifying another's social value appears well designed to allocate status, including positions of leadership, to individuals capable of solving problems of collective action and group living (Durkee et al., 2020; Garfield et al., 2020; Lukaszewski et al., 2016; Price \& Van Vugt, 2014; Redhead et al., 2021; von Rueden et al., 2014). People utilize various cues to infer conspecifics' social affordances, frequently rooted in heuristic associations between these features and behavioral repertoires that could implicate individuals as an opportunity or threat for salient social goals (Sng et al., 2020; Zebrowitz \& Montepare, 2006).

Identifying others' physical formidability, often through cues of physical strength or aggressiveness, likely functioned ancestrally to aid in selecting coalition members who would have been able to contribute to intergroup defense (Wrangham \& Peterson, 1996). Given the historically greater likelihood of men's engagement in physical conflict due to various selection pressures (e.g., intrasexual competition), men's strength became a critical component of their social capital in ancestral societies (McDonald et al., 2012; Puts, 2010; Sell et al., 2012). Men's formidability is quickly and accurately identified through physical features (Durkee et al., 2018; Sell et al., 2009), and perceivers allocate status toward physically strong men to engage other groups and enforce intragroup rules, given their probabilistic advantage in those roles (Lukaszewski et al., 2016).

With the physical advantages strong men enjoy could have come the emergence of concomitant attitudes about systems in which resources are allocated among group members. Their advantage could likely calibrate them to endorse aggressive social bargaining strategies 
that favor those capable of winning in physical conflicts, which would form the basis of a preferred social structure that codifies competition. Adaptationist hypotheses predict that formidability is associated with greater endorsement of social rules that favor competition, typifying aspects of conservative ideologies in modern societies (e.g., Petersen et al., 2013;

Petersen \& Laustsen, 2019; Price et al., 2017). Because of potential physical asymmetry between coalition members, cues to formidability may be utilized as heuristic cues of one's coalitional status. Cues to male formidability, especially upper-body strength, may be one such route through which others' conservatism is inferred in men. This research sought to test whether male formidability functions as a heuristic cue of others' conservatism.

\section{Men's Physical Strength and Political Affiliation}

Members of social species have frequently engaged in physical conflict over finite resources throughout evolutionary history (Wrangham \& Peterson, 1996), a selection pressure that led to the evolution of systems wherein conflicts are resolved via mutual assessment of combatants' relative fighting ability (Archer, 1988). As formidable men's heightened bargaining power in conflict afforded them increased opportunities to acquire resources for their group, they could likely enjoy advantages in securing contested resources for themselves within their group through physical conflict and perceive themselves as more deserving for their efforts (Lukaszewski, 2013; Sell et al., 2012; von Rueden et al., 2008). Formidable men could disproportionately claim larger shares of group resources from this advantage and subsequently endorse intragroup rules that would continuate their relative advantage over physically weaker people in resource acquisition (Price et al., 2012). These group rules would have prioritized competition among its members at the expense of more egalitarian systems of resource allocation. Within modern societies, promotion of the sorts of competitive and inegalitarian 
systems of resource allocation that favor the strong over the weak may be captured in aspects of conservative ideology.

The advantage for formidable men in social bargaining, specifically, could then calibrate their attitudes to support social rules within a group that instill competition-based hierarchies that favor aggressive social bargaining to acquire resources and enforcement of group rules (Price et al., 2017). Given men's general physical strength advantage that has previously been demonstrated as an impetus behind differences in men and women's psychological calculi for navigating interpersonally competitive environments and formidable conspecifics (Brown et al., 2017; Sacco et al., 2017; Kerry \& Murray, 2021; Rodriguez \& Lukaszewski, 2020), women’s strength would be considered largely irrelevant in shaping their political ideologies due this size asymmetry (Sell et al., 2012). Within contemporary societies, such male-typical aggressive strategies appear to align with what is frequently deemed as the conservative political ideology. In fact, physically formidable men, as indexed by upper body strength, espouse more conservative ideologies (Petersen \& Laustsen, 2019). Specific ideological manifestations include physically strong men reporting higher social dominance orientation (Price et al., 2017), greater militancy (Brown et al., 2021; Sell et al., 2017), and more opposition to wealth redistribution (Petersen et al., 2013).

\section{Inferences of Formidability and Ideology}

Humans demonstrate considerable perceptual acuity in identifying men's formidability. Inferences are multimodal, with channels including lower-pitch voices (Aung et al., 2021), facial width-to-height ratios (e.g., Třebický et al., 2013), and tall statures (e.g., Lukaszewski et al., 2016). Possibly one of the more direct modalities through which men's formidability is inferred includes physical features connoting upper body strength (e.g., arms, chest), which serve as 
putative cues to men's physical prowess (Sell et al., 2012) and is identified by perceivers with considerable automaticity (Durkee et al., 2018). Within these inferences of formidability through upper body cues is recognition of social affordances related to one's capabilities to facilitate optimal group living (Lukaszewski et al., 2016). Physically strong men are disproportionately likely to assume high status leadership roles in various societies (von Rueden \& Van Vugt, 2015). Such assortment of men based on their physical features could consequently shape downstream inferences about their attitudes about social structures, particularly those that would facilitate the continuation of a social structure favoring them.

Within these formidability inferences is acuity toward potential coalitional status. Individuals demonstrate above-chance accuracy at correctly categorizing politicians and lay individuals as conservative or liberal through simply viewing images of their faces (Rule \& Ambady, 2010; Samochowiec et al., 2010). The basis of inferring conservatism was perceivers' heuristic association of conservatism with behavioral dominance, suggesting inferred formidability could be a similarly utilized heuristic, given that facial structures indicative of dominance are veridical cues to upper body strength (Holzleitner \& Perrett, 2016; Price et al., 2017). Such inferences could be functional in facilitating identification of coalitional status and potentially relative capabilities to facilitate or impede for group living. The associations between formidability and conservatism, both from self-report and inferences, would make it seem sensible to predict men's upper body strength is perceived as a heuristic for conservatism (e.g., Petersen \& Laustsen, 2019; Price et al., 2017).

\section{Current Research}

The purpose of this current program of research is to provide a social perceptual corollary to previously documented findings indicating a link between men's espoused conservatism and 
physical strength (e.g., Petersen et al., 2013; Price et al., 2017). That is, these studies seek to demonstrate that inferences of formidability through upper body strength connote conservatism, given that physically strong men rely on competition-based resource allocation and prefer social hierarchies (e.g., Price et al., 2011). Because of the sexual dimorphism that makes physical strength more crucial toward men's survival and reproductive success than women's (Lassek \& Gaulin, 2009; Sell et al., 2012) and that upper body strength is less reliably predictive of ideology in women (Petersen et al., 2013), we exclusively considered male targets.

We conducted Study 1 to identify a perceptual corollary to the association between formidability and ideology while additionally considering whether these perceptions were specific to attitudes toward resource allocation (i.e., fiscal conservatism) or maintenance of social structures (i.e., social conservatism). Study 2 sought to provide a perceptual corollary to support either a complex or simple social bargaining model (see Petersen et al., 2013; Price et al., 2017). That is, we were interested in identifying whether formidable men would be perceived as more conservative when they secured greater access to resources. We finally conducted Study 3 to identify whether formidability is utilized as a heuristic in identifying the likelihood of one's morality aligning with what is typical of conservative ideologies (i.e., moral foundations;

Graham et al., 2009). Data and materials for all three studies are available at:

https://osf.io/fx7g3/?view only=3bfc3b768a4d440197416c636523c6dc

\section{Study 1}

The goal of this initial study was to demonstrate that physically strong men are perceived as more conservative while also identifying any potential granularity in these conservatis $\mathrm{m}$ perceptions. Strong men espouse more conservative viewpoints in both social and fiscal domains (Petersen et al., 2013; Price et al., 2017), so we sought to determine whether one or both aspects 
of conservatism vary with perceived strength of a social target. Although social and fiscal conservatism are typically related, they remain nonetheless separate entities with modest correlations (Chen \& Lind, 2005), and individuals not necessarily being both socially and fiscally conservative (e.g., libertarians; Iyer et al., 2012).

\section{Method}

Participants. A power analysis for a within-subject comparison indicated 178 participants would suffice in detecting small effects a basic $2 \times 2 \operatorname{model}($ Cohen's $f=0.15 ; 1$ $\beta=0.8)$. We deliberately oversampled in the event of potential exclusions and recruited 203 undergraduates from a public university in the Southeastern U.S. in exchange for course credit (153 women, 49 men, 1 undisclosed; $M_{\text {Age }}=20.26, S D=3.94 ; 53.2 \%$ White). Data were not analyzed until a specified stop date after reaching sufficient power. No data warranted exclusion.

\section{Material and Procedure}

Target Strength. Participants evaluated political opinions of 8 unique identities. Importantly, 4 bodies were of physically strong men and 4 bodies of physically weak men, all of whom were White and photographed in white tank tops for standardization. Strength of each target man was ascertained by an electronic dynamometer on which the targets provided both measures of their chest/arm strength through a chest press and their dominant hand grip strength, that became a composite measure of their upper body strength that is highly correlated with fighting ability (Lukaszewski et al., 2016; Sell et al., 2012). Targets categorized as strong exhibited significantly greater upper body strength, which was accurately inferred by perceivers in these original studies (see Figure 1 for example bodies).

Participant evaluated one of two versions of each unique identity. That is, unique identities were heads of each target that were either left on the original body or placed on a 
matched body, with participants evaluating two original and two matched-body targets for both categories of targets. Which versions of each unique identity participants viewed was determined through random assignment to counterbalanced blocks. Participants did not view the same unique identity twice. As an internal manipulation check, participants indicated how strong each target body appeared (1=Not Strong at All; 4=Average; $7=$ Very Strong).

Politics. We considered attitudes through two different dependent variables to test the full extent of strength perceptions influencing political perceptions.

Political Identity. Participants indicated the extent to which targets identified as liberal/conservative using two 7-point scalar items assessing political beliefs along fiscal and social dimensions (1=Very Liberal; 4=Moderate; 7=Very Conservative).

Political Issues. To determine the full extent of strength as a cue to political affiliation beyond identity, we assessed perceptions of the extent to which targets agreed with specific issues along 7-point scales (1=Strongly Disagree; $7=$ Strongly Agree) with higher scores indicating perceptions of more conservative stances. This included 3 items assessing fiscally conservative sentiments (opposition to wealth redistribution, opposition to higher taxes, opposition to government welfare programs) and 3 items assessing socially conservative sentiments (opposition to immigration, opposition to abortion, support for traditional values). The internal consistency of these issues across categories prompted us to collapse them into a composite measure of issue endorsements $(\alpha \mathrm{s}>0.74)$.

Upon entering the laboratory, consenting participants were informed on the difference between fiscal and social conservatism/liberalism as a universal refresher. They indicated their perceptions toward targets before providing demographic information and being debriefed. 


\section{Results}

Basic Comparisons. Strong men $(M=4.36, S D=0.90)$ were perceived as stronger than weak men $(M=3.07, S D=0.83), t(202)=17.81, p<0.001, d=1.48,95 \%$ CI $[1.14,1.43]$. Strong men $(M=4.03, S D=0.65)$ were additionally perceived to endorse conservative stances more than weak men $(M=3.84, S D=0.64), t(202)=4.03, p<0.001, d=0.28,95 \%$ CI $[0.09,0.28]$.

Political Identity. We conducted an initial 2 (Target Strength: Strong vs. Weak) $\times 2$ (Viewpoint Type: Fiscal vs. Social) repeated-measures ANOVA. A Target Strength main effect indicated strong targets were perceived as more conservative $(M=4.13, S D=0.87)$ than weak targets $(M=3.91, S D=0.89), F(1,202)=9.04, p=0.003, \eta_{p}{ }^{2}=0.043$. Subsequent one-sample $t$-tests weighted against the mid-point of 4 (i.e., perceptions of being moderate) indicated strong men are perceived as categorically conservative, $t(202)=2.41, p=0.017, d=0.17,95 \% \mathrm{CI}[0.02,0.24]$. Weak men were perceived as neither conservative nor liberal, $t(202)=-1.41, p=0.160, d=0.10$, 95\% CI [-0.19, 0.03]. ${ }^{1}$ Neither the Viewpoint Type main effect nor the interaction were significant, $F \mathbf{S}<0.82, p \mathrm{~s}>0.368$.

\section{Discussion}

Results provided initial evidence that formidability assessments form a partial basis of inferring men's conservatism. When synergizing the basis of our findings with a recalibration perspective of formidability assessment (Sell, 2011), our results suggest a perceptual corollary to the social bargaining model demonstrating that physically strong men adopt more conservative ideologies that could potentially continuate enactment of social rules favoring their advantages in resource access and ascension of a hierarchy (Price et al., 2017). Although such results remain theoretically sensible, there may be a level of nuance for which the design of this experiment could not account, thus limiting the full extent of our inferential capacity. Because physically 
strong men can command access to resources and typically higher status (e.g., Lukaszewski, 2013; von Rueden et al., 2014), perhaps strong men's wealth and status informs perceptions of conservatism in a complementary fashion. Study 2 sought to address this possibility.

\section{Study 2}

Although Study 1 found strong men are perceived as more conservative than weak men, it did not consider a critical caveat that qualified previous social bargaining model findings. Whereas a simple social bargaining model would suggest strong men are unilaterally more conservative, a complex social bargaining model would indicate men's strength would only predict conservatism among those atop a social hierarchy (Petersen et al., 2013; Price et al., 2017). Previous research shows economically advantaged individuals are perceived as possessing a slow life history strategy, a reproductive strategy favoring resource acquisition prior to childrearing that is typical of conservative individuals (Williams et al., 2016) and considered requisite in facilitating their typical social strategies (Sinn \& Hayes, 2018).

Conversely, among formidable men without access to resources, status hierarchy ascension may be difficult and could limit the benefit of conservative social policies to formidable men with resource access. Previous findings have indicated complexity in social bargaining models by indicating physically strong men of low socioeconomic status (SES) endorse redistributive economic policies (Petersen et al., 2013; Price et al., 2017; but see Petersen \& Laustsen, 2019). Such endorsement itself would be strategic, as it could afford access to resources through restrictive government policies that require cession of resources to them.

This nuance led us to conduct Study 2 with a pair of competing hypotheses. Evidence consistent with a simple social bargaining model of men's formidability, wherein judgments of men's strength is unilaterally diagnostic of interest in aggressive competition, would be 
perceptions of strong men as more conservative regardless of SES. Conversely, evidence consistent with a complex model would be perceptions of formidable men as more conservative when they are wealthy.

\section{Method}

Participants. We recruited 302 undergraduates from a public university in the Southeastern U.S. in exchange for course credit through online data collection (228 women, 71 men, 3 identified as other; $M_{A g e}=20.46, S D=4.51 ; 60.6 \%$ White). We employed recruitment strategy as Study 1 with a power analysis indicating we were sufficiently powered to detect small effects $(f=0.15,1-\beta=0.80)$. No data warranted exclusion.

\section{Materials and Procedure}

Participants viewed the targets in a similar capacity as Study 1. However, targets were also paired with a statement indicating their hypothetical income relative to the reported median income in the city of the university in question (i.e., $\$ 35,000$ ), which served as a proxy for targets' SES. Incomes above the median (all above \$80,000) indicated high SES and below indicating low SES (all below \$26,000). This led to each participant viewing two strong highSES targets, two strong low-SES, two weak high-SES, and two weak low-SES who identities were counterbalanced randomized like in Study 1.

Along with asking participants' perceptions of targets' political identity (both fiscal and social) and strength in similar capacity to Study 1, we tasked participants to indicate the extent to which they agreed with a statement implicating the targets as wealthy $(1=$ Strongly Disagree; 7=Strongly Agree). Finally, participants provided demographic information and were debriefed.

\section{Results}

Basic Comparisons. Strong men $(M=4.05, S D=0.95)$ were perceived as stronger than 
weak mean $(M=3.03, S D=0.93), t(301)=18.99, p<0.01, d=1.09,95 \%$ CI $[0.91,1.12]$. High-SES men $(M=3.98, S D=1.43)$ were additionally perceived as wealthier than low-SES men $(M=2.26$, $S D=0.92), t(301)=19.01, p<0.001, d=1.09,95 \%$ CI $[1.54,1.89]$.

Primary Analyses. We conducted a 2 (Target Strength: Strong vs. Weak) $\times 2$ (Target SES: High vs. Low) $\times 2$ (Viewpoint Type: Fiscal vs. Social) repeated-measures ANOVA. A Target Strength main effect indicated strong men were perceived as more conservative $(M=4.20$, $S D=1.25)$ than weak men $(M=4.04, S D=1.31), F(1,301)=9.73, p=0.002, \eta_{p}{ }^{2}=0.031$. Subsequent one-sample $t$-tests indicated participants perceived strong targets as categorically conservative, $t(301)=3.96, p<0.001, d=0.23,95 \%$ CI $[0.10,0.30]$. No categorical perception emerged for weak targets, $t(301)=0.82, p=0.411, d=0.04,95 \% \mathrm{CI}[-0.06,0.15]$.

An additional Target SES main effect indicated high-SES targets were perceived as more conservative $(M=4.30, S D=1.26)$ than low-SES targets $(M=3.94, S D=1.31), F(1,301)=19.98$, $p<0.001, \eta_{p}{ }^{2}=0.062$. Finally, a Viewpoint Type main effect indicated targets were perceived as more fiscally conservative $(M=4.16, S D=1.31)$ than socially conservative $(M=4.08, S D=1.26)$, $F(1,301)=5.51, p=0.020, \eta_{p}^{2}=0.018$. No interactions emerged, $F \mathbf{s}<2.87, p \mathrm{~s}>0.091$.

\section{Discussion}

Results align with a simple social bargaining model. Strong men were perceived as more conservative regardless of SES. Support for a simple bargaining model may be unsurprising, given the strong signal value of formidability inferred through men's bodies and the automaticity in inferring aggression through these cues (Durkee et al., 2018; Sell et al., 2009, 2011).

Inferences could serve to identify men's proclivity to engage in aggressive competition, which could be heuristically associated with modern conservatism and impede additional affordance judgments. Alternatively, this study's manipulation for wealth could have limited communicative 
properties, given the rich targets' average rating for perceived wealth being below the scalar midpoint, which could only afford perceptions of relative wealth instead of categorical wealth.

An additional main effect emerged that was consonant with previous findings regarding ideological differences in coalition status. Specifically, high-SES targets were perceived as more conservative. Assortment into intragroup coalitions could occur along boundaries of relative access to resources that could ostensibly position high-SES men into endorsing rule enactment that favors hierarchy ascension through competition. Indices of wealth on both individual and coalitional levels are associated with reduced endorsement of intragroup wealth redistribution (Luberti et al., 2020; Sznycer et al. et al., 2018) and heightened endorsement of aggressive intergroup relations (Brown et al., 2021). Perceivers could utilize resource access as a cue to functionally identify targets' coalition status. Within these inferences of coalitional status could be additional related inferences of morality that would be most typical of a given ideology. Study 3 sought to extend findings to consider moral foundation differences and whether formidability elicits perceptions of endorsement for them.

\section{Study 3}

Identification with a conservative ideology can be motivated by myriad attitudinal factors, including morality. People's justification of political ideologies through morality would lead them to endorse social policies that could facilitate enactment of rules aligning with these ideologies and place them at a higher status within their group. According to Moral Foundations Theory (Graham et al., 2013), conservatives frequently base their morality in concerns related to fostering group cohesion through adherence to traditional values (i.e., ingroup loyalty, respect for authority, disgust), which they would ostensibly believe themselves as more moral than liberal group members (Graham et al., 2009). This could suggest morality for conservatives has roots in 
establishing group hierarchies. This grounding in tradition could further be at the expense of considering morality from perspectives of care and fairness typical of liberal ideologies. In fact, strong men's morality is less rooted in concerns of fairness and care (Brown et al., 2021).

This disinterest in liberal foundations could be related to formidable men's reliance on aggressive social bargaining strategies from which one could infer through perceptions of strong men's interest in competition. The purpose of Study 3 was to determine whether formidability similarly provided a heuristic to the basis of men's morality. We first predicted individuals would perceive morality of formidable men as more rooted in so-called conservative foundations and less in liberal foundations. Because of this reliance on aggressive bargaining, formidable men could also be perceived as placing greater valuation in moral foundations pertaining to liberty, given its emphasis on market competition that could have historically advantaged strong men in resource acquisition in a manner typical of fiscal conservatism (Iyer et al., 2013).

\section{Method}

Participants. We recruited 179 participants from a public university in Southeastern U.S. in exchange for course credit (92 men, 84 women, 3 identifying as neither, 1 undisclosed; $M_{\text {Age }}=19.54, S D=2.42 ; 83.3 \%$ White). A power analysis indicated 164 participants would sufficiently detect small effects when considering interactive effects $(f=0.10,1-\beta=0.80)$. No data warranted exclusion.

Materials and Procedures. Participants evaluated the same targets from the previous two studies using the same randomization and counterbalancing. In addition to responding to the same item assessing target strength, participants additionally indicated the extent to which 12 different statements were relevant to the targets' morality. These statements were derived from the revised factor structure of the Moral Foundation Questionnaire that considered perceptions of 
relevance for various issues to a person's morality (Harper \& Rhodes, in press). Unlike the initial conceptualizations of this measure that considered moral foundations along five dimensions (e.g., Graham et al., 2009), this structure considered three dimensions of morality along dimensions of traditionalism, compassion, and liberty, which ostensibly provide a more parsimonious conceptualization of moral foundations.

The traditionalism factor was comprised of items derived from those previously defined as part of purity, ingroup loyalty, and respect for authority (e.g., "This person believes respect is something all children need to learn"). Compassion was derived from care and fairness (e.g., "This person would be really upset if someone was cruel to another person"). Liberty was derived from a later-defined factor that specifically libertarian ideologies (e.g., "This person believes the government interferes far too much in everyday lives"; Iyer et al., 2012). Items operated along 7-point scales (1=Completely Irrelevant; $7=$ Completely Relevant $)$, with four items representing each factor that were presented in random order $(\alpha \mathrm{s}>0.87)$.

\section{Results}

Basic Comparison. Strong men were perceived as stronger $(M=4.56, S D=0.89)$ than weak men $(M=2.99, S D=0.86) t(178)=25.57, p<0.001, d=1.91,95 \%$ CI $[1.66,2.15]$.

Primary Analyses. We conducted a 2 (Target Strength: Strong vs. Weak) × 3 (Moral Foundation: Tradition vs. Compassion vs. Liberty) repeated ANOVA. Discrepancies in degrees of freedom are based in adjustments for sphericity violations through Greenhouse-Geisser corrections. A Target Strength main effect indicated strong targets were perceived as endorsing the moral foundations to a greater degree $(M=4.04, S D=1.10)$ than weak targets $(M=3.95$, $S D=1.09), F(1,178)=2.25, p=0.008, \eta_{p}{ }^{2}=0.039$. A Moral Foundation main effect additionally emerged, $F(1.73,307.79)=2.25, p<0.001, \eta_{p}{ }^{2}=0.088$. Targets were perceived as having liberty as 
most relevant to their morality $(M=4.15, S D=1.09)$, followed by tradition $(M=3.98, S D=1.08)$, and then compassion $(M=3.87, S D=1.10)$; subsequent LSD tests indicated these scores were all significantly different from each other $(p \mathrm{~s}<0.045, d \mathrm{~s}>0.10)$.

A Target Strength $\times$ Moral Foundation interaction emerged, $F(1.73,308.55)=16.47$, $p<0.001, \eta_{p}{ }^{2}=0.085$ (see Figure 2). Simple effects tests indicated strong targets were perceived as having traditionalism being more relevant to their morality $(M=4.06, S D=1.09)$ than weak targets $(M=3.90, S D=1.08), F(1,178)=9.55, p=0.002, \eta_{p}{ }^{2}=0.053,95 \%$ CI $[0.05,0.25]$. Strong targets were additionally perceived as having liberty $(M=4.27, S D=1.13)$ being more relevant to their morality than weak targets $(M=4.04, S D=1.06), F(1,178)=23.66, p<0.001, \eta_{p}{ }^{2}=0.117,95 \% \mathrm{CI}[-$ $0.22,-0.01]$. Conversely, weak targets were perceived as having compassion as being more relevant to their morality $(M=3.93, S D=1.13)$ than strong targets $(M=3.81, S D=1.08), F(1$, $178)=4.52, p=0.035, \eta_{p}{ }^{2}=0.025,95 \%$ CI $[0.14,0.33]$.

Viewed another way, a pair of significant simple effects emerged comparing the scores of strong and weak targets separately, $F \mathrm{~s}>5.21, p \mathrm{~s}<0.007$. The effect size for strong targets was magnitudinally larger $\left(\eta_{p}{ }^{2}=0.223\right)$ than for weak targets $\left(\eta_{p}^{2}=0.056\right)$. Subsequent pairwise comparisons indicated liberty was the most relevant dimension to strong targets, followed by traditionalism, and then compassion; all scores were significantly different from each other $(p \mathrm{~s}<0.001, d s>0.18)$. For weak targets, liberty was most relevant to their morality, followed by compassion, and then traditionalism. The liberty perception was significantly more relevant than traditionalism $(p=0.001, d=0.13)$. The differences between compassion with both traditionalism and liberty were not significant $(p \mathrm{~s}>0.088, d \mathrm{~s}<0.11)$.

\section{Discussion}

This study found converging evidence for how formidability is utilized as a heuristic cue 
for conservatism in domains of morality. Traditionalism and liberty were more relevant to strong men's morality compared to weak men, with compassion being irrelevant to strong men. These findings suggest formidability similarly connotes the epistemic basis for one's alignment with a given coalition, with strong men being perceived as more likely to center their morality around individual freedom that could afford them greater access to resources and adherence to traditions that could continuate hierarchies wherein they would have advantages (see Sinn \& Hayes, 2018). This valuation of autonomy could further justify their use of aggressive social bargaining. Interestingly, liberty was perceived as the most relevant domain for strong men, which could be rooted in perceptions of their reliance on aggressive bargaining that could be seen as a basis for success (Price et al., 2017). Strong men's endorsement of liberty could further reflect perceptions of a disinterest in government regulation that could preclude them from employing their preferred bargaining strategies. It should nonetheless be noted that weak men's morality also appeared most rooted in liberty, though this perception was not as large as it was for strong men, which could reflect strong men's salient bargaining power through their formidability. The signal value of physical weakness was less diagnostic of men's moral foundations, with greater variability in perceptions of weak targets. This could provide further evidence of weakness having an orthogonal signal value that provides limited information regarding coalitional status.

\section{General Discussion}

Results from this program of research indicate individuals utilize visual cues of upper body strength as a heuristic cue to infer additional information about their coalition status and related motivations. Formidable men are perceived as espousing conservative viewpoints. Such findings provide a social perceptual corollary for work concerning social bargaining models of resource and status acquisition, which posits physically strong men are perceived as more 
conservative (e.g., Petersen et al., 2013; Price et al., 2011, 2017). Our results suggest such political affiliations can ultimately be inferred based on perceptions of formidability (Sell et al., 2009), which could be the basis of accurate inferences of conservatism (Rule \& Ambady, 2010). Findings provide initial evidence for an affordance management framework for formidability cues informing functional perceptions of bargaining strategies (Sng et al., 2020).

Coalitional inferences could facilitate recognizing myriad social affordances, particularly related to the costs and opportunities of formidable male conspecifics in group living (e.g., Lassetter et al., in press). Formidable men could represent costs through their reliance on aggressive social bargaining, which could threaten resource acquisition goals of opposing coalition members, particularly coalitions favoring egalitarianism (Price et al., 2017). Conversely, formidability could represent an opportunity to ensure group access to resources through increased intergroup protection in competitive environments among those affiliating with formidable coalition members (Brown et al., 2017,2021), particularly among individuals seeking affiliation to reap the benefits of group living from their own coalition (e.g., Brown et al., 2019). Recognizing formidable men's interest in aggressive social bargaining appears to elicit a downstream stereotype of endorsing conservative policies, as evidenced by both studies eliciting an inference of strong men as categorically conservative.

Interestingly, categorical tests indicating physically strong men are perceived as conservative additionally indicated weak men were perceived as neither conservative nor liberal. This suggests that the basis of affordance judgments for liberal ideologies through physical features may be unrelated to formidability. It is possible inferences of liberal ideologies could be rooted in perceptions of warmth, which is orthogonal to the dominance connoted through formidability (Oosterhof \& Todorov, 2008). Liberals prefer leaders possessing warm traits 
(Laustsen \& Petersen, 2016), which could be functionally rooted in selecting coalitions averse to antagonism. Future research could present faces varying in levels of warmth and dominance for participants to assess the ideology of these orthogonal dimensions.

Studies 1 and 2 additionally demonstrated perceptions of conservatism was not specific to any domain of conservatism. This could suggest considerable overlap between the ancestral goals of formidable men that manifest as modern conservatism, which covers different interpersonal strategies within different groups (Sinn \& Hayes, 2018). The fiscal dimension may represent interest in resource allocation, wherein formidable men would have been advantaged in direct competition. The social dimension could represent interest in instilling rigid social hierarchies that could facilitate increased aggressive intergroup contact favored by formidable men (Price et al., 2017; Sell et al., 2017). Results from Study 3 provide converging evidence that formidability connotes endorsement of relatively more conservative ideologies by demonstrating perceptions of strong men's endorsement of tradition and liberty that could respectively represent social and fiscal domains. Nonetheless, these domains remain distinct coalitional identities (Chen \& Lind, 2005), which could warrant nuance to identify which components of libertarian ideology can be inferred through physical features (e.g., free markets versus drug legalization).

\section{Limitations and Future Directions}

Results provide evidence for perceptual corollaries to the strength-conservatism link that implicates upper body strength (Laustsen \& Petersen, 2019), yet remain limited. Our findings merely indicate the presence of a stereotype for formidable men but not whether demonstrating formidability is a veridical cue to ideology. These stimuli were not pre-tested to identify the political affiliations of each target. Conservatism can be accurately inferred through dominant facial features (Rule \& Ambady, 2010; Samochowiec et al., 2010), although facial formidability 
is not associated with conservatism (Saribay \& Kleisner, 2018). Given that facial dominant is a veridical cue of upper body strength (Holzleitner \& Perrett, 2016; Sell et al., 2009) and formidable men feel more entitled to resources following conflict (Sell et al., 2012), inferences of conservatism may nonetheless be possible through concomitant indices of body formidability. Future research would benefit from generating stimuli normed for both formidability and conservatism to identify whether these inferences are rooted in a kernel of truth.

Additionally, despite the consistent difference in perceptions of strength, perceptions of physical strength as diagnostic of a target being categorically conservative are rooted in small effects. This small effect could reflect that the ancestral bases of these affordance judgments could be less salient in modern contexts, wherein physical conflict is less likely to occur. The small effect may further reflect the imperfect overlap between a linguistic distinction of conservatism with the aggressive behavioral repertoire that may underpin it.

Humans utilize a variety of physical features as the basis of their formidability-based stereotyping. The current findings' focus on upper body strength could benefit from consideration of additional cues to identify potential interactive or independent effects. For example, whereas US citizens perceive formidability as more threatening in Black men than White men (Wilson et al., 2017), other affordance judgments do not elicit cross-race differences (Deska et al., 2017; Brown et al., in press). Future studies could identify whether perceptions of conservatism through formidability are limited to White targets or if they generalize to other racial categories. Another concern of generalizability emerges with how conservatism could be inferred cross-culturally. Although this link between conservatism and strength emerges crossculturally (e.g., Petersen et al., 2013; Price et al., 2017), results in the current study could have been bound to conceptualizations of conservatism specific to the United States; future work 
would benefit from conceptually replicating these effects in other cultures. Specifically, if these heuristics are rooted in perceptions of men's advantage in resource competition, these inferences should be most apparent in cultures experiencing greater competition for resources to identify group members who could pose a resource threat.

Another future direction includes identifying the cues of political affiliation in women. Although a growing body of evidence indicates women's strength is predictive of individual differences in interpersonal bargaining strategies within certain ecologies (Kerry \& Murray, 2019; von Rueden et al., 2015), the sexual dimorphism for engaging in physical conflict and its resulting size asymmetry would likely limit the diagnosticity of upper body strength in social affordances to men (Lassek \& Gaulin, 2009; Puts, 2010; Palmer-Hague et al., 2018). In fact, accurate inferences of conservatism in female faces are highest among targets with heightened female facial typicality that would connote less formidability (Carpinella \& Johnson, 2013). Attractive women's bargaining power, itself based in femininity, positions them to prefer competitive strategies (Lukaszewski, 2013). Future studies could specifically identify which physical features deemed attractive in women (e.g., low waist-to-hip ratio) are most associated with perceptions of conservatism to determine whether attractiveness-based bargaining power heightens favorability.

The interest in allocating status to physically strong men could also provide impetus to consider whether the formidability preference is specific to certain coalitions. Physically strong men could be motivated to enact social policies that favor competition or aggressive intergroup bargaining. Cues to interpersonal dominance are preferred among conservative voters seeking to address outgroup threats and are implicated in assessments of individuals' ability to punish free riders (Laustsen et al., 2015; Laustsen \& Petersen, 2017, 2015; Lukaszewski et al., 2016). Future 
research would benefit from determining the extent to which formidability shapes electoral preferences among different voting coalitions.

\section{Conclusion}

Research suggests formidability is associated with endorsement of aggressive social bargaining strategies typifying modern conservative ideologies. Our research identified a potential evolved psychological calculus in identifying conspecifics' ideology through physical affordance judgments through upper body strength, with formidability heightening perceptions of conservatism. Our findings represent an ancestral basis to coalitional inferences of men's intragroup status. 


\section{References}

Archer, J. (1988). The Behavioural Biology of Aggression. Cambridge.

Aung, T., \& Puts, D. (2020). Voice pitch: a window into the communication of social power. Current Opinion in Psychology, 33, 154-161.

Barbaro, N., Mogilski, J. K., Shackelford, T. K., \& Pham, M. N. (2018). Men’s interest in allying with a previous combatant for future group combat. Human Nature, 1-9.

Brown, M., Chua, K. J., \& Lukaszewski, A. W. (2021). Formidability and socioeconomic status uniquely predict militancy and political moral foundations. Personality and Individual Differences, 168, 110284.

Brown, M., Sacco, D. F., \& Barbaro, N. (in press). Formidable male facial structures influence postconflict reconciliation judgments. Evolutionary Behavioral Sciences.

Brown, M., Sacco, D., Barbaro, N., \& Drea, K. (2021). Contextual factors that heighten interest in coalitional alliances with men possessing formidable facial structures.

Brown, M., Sacco, D. F., Lolley, K. P., \& Block, D. (2017). Facing the implications: Dangerous world beliefs differentially predict men and Women's aversion to facially communicated psychopathy. Personality and Individual Differences, 116, 1-5.

Brown, M., Sacco, D. F., \& Medlin, M. M. (2019). Approaching extraverts: Socially excluded men prefer extraverted faces. Personality and Individual Differences, 137, 198-203.

Carpinella, C. M., \& Johnson, K. L. (2013). Politics of the face: The role of sex -typicality in trait assessments of politicians. Social Cognition, 31, 770-779.

Chen, D. L., \& Lind, J. T. (2005). The political economy of beliefs: Why fiscal and social conservatives and liberals come hand-in-hand. Unpublished paper.

Deska, J. C., Lloyd, E. P., \& Hugenberg, K. (2018). Facing humanness: Facial width-to-height 
ratio predicts ascriptions of humanity. Journal of Personality and Social Psychology, 114, 75-94.

Durkee, P. K., Goetz, A. T., \& Lukaszewski, A. W. (2018). Formidability assessment mechanisms: Examining their speed and automaticity. Evolution and Human Behavior, $39,170-178$.

Durkee, P. K., Lukaszewski, A. W., \& Buss, D. M. (2020). Psychological foundations of human status allocation. Proceedings of the National Academy of Sciences, 117, 21235-21241.

Garfield, Z. H., Syme, K. L., \& Hagen, E. H. (2020). Universal and variable leadership dimensions across human societies. Evolution and Human Behavior, 41, 397-414.

Graham, J., Haidt, J., Koleva, S., Motyl, M., Iyer, R., Wojcik, S. P., \& Ditto, P. H. (2013). Moral foundations theory: The pragmatic validity of moral pluralism. Advances in Experimental Social Psychology, 47, 55-130.

Graham, J., Haidt, J., \& Nosek, B. A. (2009). Liberals and conservatives rely on different sets of moral foundations. Journal of Personality and Social Psychology, 96, 1029-1046.

Harper, C. A., \& Rhodes, D. (in press). Reanalysing the factor structure of the Moral Foundations Questionnaire. British Journal of Social Psychology.

Hehman, E., Leitner, J. B., Deegan, M. P., \& Gaertner, S. L. (2015). Picking teams: When dominant facial structure is preferred. Journal of Experimental Social Psychology, 59, $51-59$.

Holzleitner, I. J., \& Perrett, D. I. (2016). Perception of strength from 3D faces is linked to facial cues of physique. Evolution and Human Behavior, 37, 217-229.

Iyer, R., Koleva, S., Graham, J., Ditto, P., \& Haidt, J. (2012). Understanding libertarian morality: The psychological dispositions of self-identified libertarians. PLoS One, 7, e42366. 
Kerry, N., \& Murray, D. R. (2021). Physical strength partly explains sex differences in trait anxiety in young Americans. Psychological Science, 32, 809-815.

Kerry, N., \& Murray, D. R. (2019). Is formidability associated with political conservatism? Evolutionary Psychological Science, 5, 220-230.

Lassek, W. D., \& Gaulin, S. J. (2009). Costs and benefits of fat-free muscle mass in men: Relationship to mating success, dietary requirements, and native immunity. Evolution and Human Behavior, 30, 322-328.

Lassetter, B., Hehman, E., \& Neel, R. (in press). The relevance appraisal matrix: Evaluating others' relevance. Journal of Personality and Social Psychology.

Laustsen, L., \& Petersen, M. B. (2015). Does a competent leader make a good friend? Conflict, ideology and the psychologies of friendship and followership. Evolution and Human Behavior, 36, 286-293.

Laustsen, L., \& Petersen, M. B. (2016). Winning faces vary by ideology: How nonverbal source cues influence election and communication success in politics. Political Communication, $33,188-211$.

Laustsen, L., \& Petersen, M. B. (2017). Perceived conflict and leader dominance: Individual and contextual factors behind preferences for dominant leaders. Political Psychology, 38, 1083-1101.

Luberti, F. R., Blake, K. R., \& Brooks, R. C. (2020). The effects of the mating market, sex, age, and income on sociopolitical orientation. Human Nature, 31, 88-111.

Lukaszewski, A. W. (2013). Testing an adaptationist theory of trait covariation: Relative bargaining power as a common calibrator of an interpersonal syndrome. European Journal of Personality, 27, 328-345. 
Lukaszewski, A. W., Simmons, Z. L., Anderson, C., \& Roney, J. R. (2016). The role of physical formidability in human social status allocation. Journal of Personality and Social Psychology, 110, 385-406.

McDonald, M. M., Navarrete, C. D., \& Van Vugt, M. (2012). Evolution and the psychology of intergroup conflict: The male warrior hypothesis. Philosophical Transactions of the Royal Society: Biological Sciences, 367, 670-679.

Oosterhof, N. N., \& Todorov, A. (2008). The functional basis of face evaluation. Proceedings of the National Academy of Sciences, 105, 11087-11092.

Petersen, M. B., \& Laustsen, L. (2019). Upper-body strength and political egalitarianism: Twelve conceptual replications. Political Psychology, 40, 375-394.

Petersen, M. B., Sznycer, D., Sell, A., Cosmides, L., \& Tooby, J. (2013). The ancestral logic of politics: Upper-body strength regulates men's assertion of self-interest over economic redistribution. Psychological Science, 24, 1098-1103.

Price, M. E., Dunn, J., Hopkins, S., \& Kang, J. (2012). Anthropometric correlates of human anger. Evolution and Human Behavior, 33, 174-181.

Price, M. E., Kang, J., Dunn, J., \& Hopkins, S. (2011). Muscularity and attractiveness as predictors of human egalitarianism. Personality and Individual Differences, 50, 636-640.

Price, M. E., Sheehy-Skeffington, J., Sidnaius, J., \& Pound, N. (2017). Is sociopolitical egalitarianism related to bodily and facial formidability in men? Evolution and Human Behavior, 38, 626-634.

Price, M. E., \& Van Vugt, M. (2014). The evolution of leader-follower reciprocity: the theory of service-for-prestige. Frontiers in Human Neuroscience, 8, 363.

Puts, D. A. (2010). Beauty and the beast: Mechanisms of sexual selection in humans. Evolution 
and Human Behavior, 31, 157-175.

Redhead, D., Dhaliwal, N., \& Cheng, J. T. (2021). Taking charge and stepping in: Individuals who punish are rewarded with prestige and dominance. Social and Personality Psychology Compass, 15, e12581.

Rodriguez, N. N., \& Lukaszewski, A. W. (2020). Functional coordination of personality strategies with physical strength and attractiveness: A multi-sample investigation at the HEXACO facet-level. Journal of Research in Personality, 89, 104040.

Rule, N. O., \& Ambady, N. (2010). Democrats and Republicans can be differentiated from their faces. PLoS One, 5, e8733.

Sacco, D. F., Brown, M., Lustgraaf, C. J. N., \& Young, S. G. (2017). Women's dangerous world beliefs predict more accurate discrimination of affiliative facial cues. Evolutionary Behavioral Sciences, 11,309-315.

Samochowiec, J., Wänke, M., \& Fiedler, K. (2010). Political ideology at face value. Social Psychological and Personality Science, 1, 206-213.

Saribay, S. A., \& Kleisner, K. (2018). Are political views and religiosity related to facial morphology? Evidence from a Turkish sample. Personality and Individual Differences, $124,25-30$

Sell, A. N. (2011). The recalibrational theory and violent anger. Aggression and Violent Behavior, 16, 381-389.

Sell, A., Cosmides, L., Tooby, J., Sznycer, D., Von Rueden, C., \& Gurven, M. (2009). Human adaptations for the visual assessment of strength and fighting ability from the body and face. Proceedings of the Royal Society of London B: Biological Sciences, 276, 575-584.

Sell, A., Hone, L. S., \& Pound, N. (2012). The importance of physical strength to human males. 
Human Nature, 23, 30-44.

Sell, A., Sznycer, D., Cosmides, L., Tooby, J., Krauss, A., Nisu, S., ... \& Petersen, M. B. (2017). Physically strong men are more militant: A test across four countries. Evolution and Human Behavior, 38, 334-340.

Sinn, J. S., \& Hayes, M. W. Is political conservatism adaptive? Reinterpreting right-wing authoritarianism and social dominance orientation as evolved, sociofunctional strategies. Political Psychology.

Sng, O., Williams, K. E., \& Neuberg, S. L. (2020). Sex-age stereotyping: Social perceivers as lay adaptationists. Evolution and Human Behavior, 41(2), 136-149.

Sznycer, D., Ermer, E., \& Tooby, J. (2018). Why do people think that others should earn this or that? The Behavioral and Brain Sciences, 41, e189.

Třebický, V., Havlíček, J., Roberts, S. C., Little, A. C., \& Kleisner, K. (2013). Perceived aggressiveness predicts fighting performance in mixed-martial-arts fighters. Psychological Science, 24, 1664-1672.

von Rueden, C., Gurven, M., \& Kaplan, H. (2008). The multiple dimensions of male social status in an Amazonian society. Evolution and Human Behavior, 29, 402-415.

von Rueden, C., Gurven, M., Kaplan, H., \& Stieglitz, J. (2014). Leadership in an egalitarian society. Human Nature, 25, 538-566.

von Rueden, C., \& Van Vugt, M. (2015). Leadership in small-scale societies: Some implications for theory, research, and practice. The Leadership Quarterly, 26, 978-990.

Williams, K. E. G., Sng, O., \& Neuberg, S. L. (2016). Ecology-driven stereotypes override race stereotypes. Proceedings of the National Academy of Sciences, 113, 310-315.

Wilson, J. P., Hugenberg, K., \& Rule, N. O. (2017). Racial bias in judgments of physical size 
and formidability: From size to threat. Journal of Personality and Social Psychology, $113,59-80$.

Wrangham, R. W., \& Peterson, D. (1996). Demonic Males: Apes and the Origins of Human Violence. Houghton Mifflin Harcourt.

Zebrowitz, L. A., \& Montepare, J. (2006). The Ecological Approach to Person Perception: Evolutionary Roots and Contemporary Offshoots. In M. Schaller, J. A. Simpson, \& D. T. Kenrick (Eds.), Evolution and Social Psychology (pp. 81-113). Psychosocial Press. 

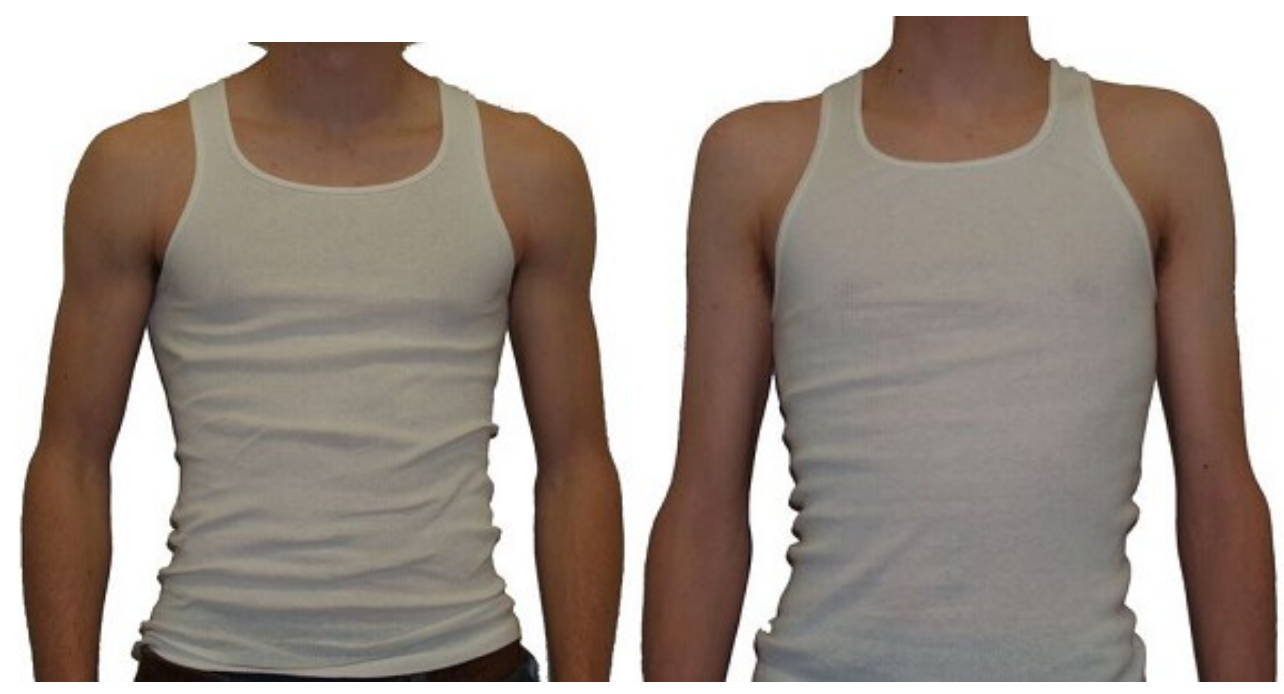

Figure 1. Example target strong (left) and weak bodies masked for confidentiality. 


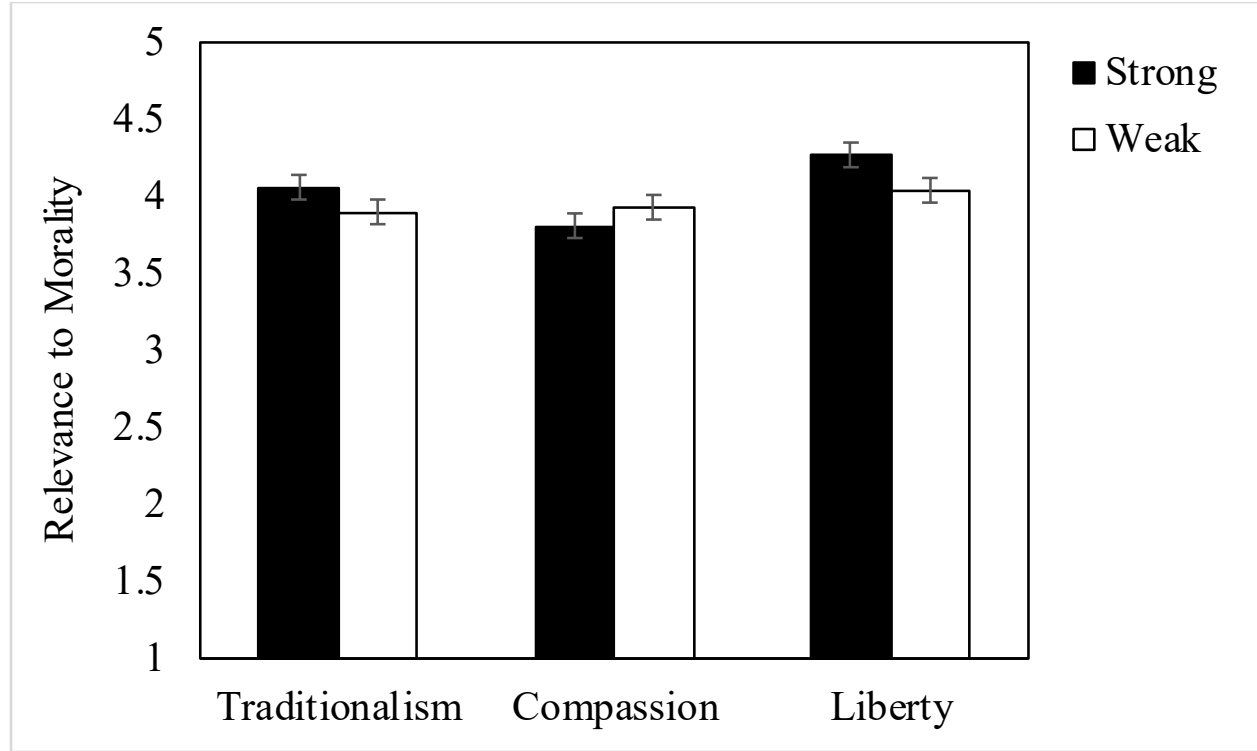

Figure 2. Perceptions of the relevance of traditionalism, compassion, and liberty to strong and weak targets' morality (with standard error bars). 


\section{Notes}

${ }^{1}$ When including the counterbalance in model for which versions of the targets that participants viewed, no interactive effects emerged between the counterbalance with Target Strength, prompting no further consideration of Counterbalance as a between-subjects factor. 